previously discovered protein, which they call $\alpha$-haemoglobin-stabilizing protein (AHSP), seems to prevent just this problem (Fig. 1).

Kihm et al. started by screening for genes that are turned on by GATA-1, a genetranscription factor that regulates the production of globins and of the enzymes required to synthesize haem ${ }^{10}$. The screen led to the identification of one gene, expressed at relatively high levels in red blood cells, whose encoded protein - AHSP — binds specifically to $\alpha$-haemoglobin in vitro; it does not bind to $\beta$-haemoglobin or to HbA. Kihm etal. also show that when $\alpha$-haemoglobin is artificially overexpressed in suitable test cells, it forms large precipitates. However, when $\alpha$-haemoglobin and AHSP are expressed in the same cells, both proteins remain distributed homogeneously throughout the cytoplasm. Similarly, AHSP prevents free $\alpha$-haemoglobin from precipitating in vitro, whether spontaneously or after the oxidation of haem. Finally, like a trulyenlightened chaperone, AHSP keeps a bound $\alpha$-haemoglobin under control only until the latter encounters the desired partner, a $\beta$-haemoglobin.

These results could have medical implications. It was realized long ago that the balance of the $\alpha$ - and $\beta$-globin chains is important not just to molecular physiology but also in blood disease. Indeed, in $\beta$-thalassaemia syndromes the main defect is by definition a substantial reduction in the rate of $\beta$-chain synthesis, leading to less $\mathrm{HbA}$ per red blood cell. When both of the two copies of the $\beta$-globin gene are defective (that is, in the homozygous state), patients suffer from severe anaemia, which they can survive only if they receive regular blood transfusions or a bone-marrow transplant from a suitable donor ${ }^{11}$.

In these patients, because of the lack of $\beta$-chains there is a relative excess of $\alpha$ chains ${ }^{12}$, and this is a major determinant of the severity of disease ${ }^{13}$. For instance, people who have a $\beta$-thalassaemia-causing mutation in just one copy of the $\beta$-globin gene (they are heterozygotes) have essentially no symptoms. However, they will develop a relatively serious condition, thalassaemia intermedia, if they also have a triplicated $\alpha$-globin gene ${ }^{14}$. Conversely, people who would normally develop severe $\beta$-thalassaemia (thalassaemia major) as a result of a homozygous $\beta$-globin mutation can have a milder condition, again thalassaemia intermedia, if they also have mutations in the $\alpha$-globin gene that reduce the concentration of the $\alpha$-chain ${ }^{15}$.

Could AHSP be relevant to these diseases? The last part of the paper by Kihm et $a l^{\text {B }}$ suggests that the answer might be yes. The authors engineered mice that lacked functional AHSP, and found remarkable changes in the animals' blood. The mice did not have thalassaemia, because their globin genes were intact. But their red blood cells showed abnormalities consistent with damage caused by unchaperoned $\alpha$-chains. This provides in vivo support for the idea that the slight excess of $\alpha$-chains in normal red blood cells is effectively neutralized by AHSP. By contrast, in homozygous $\beta$-thalassaemia patients, because there are no $\beta$-chains for the $\alpha$-chains to pair up with, the $\alpha$-chains will exceed the chaperone capacity of AHSP (the intracellular molar ratio of AHSP to $\alpha$-chains is only about $1: 50$ ). The resulting damage would cause the death of maturing red blood cells.

Kihm et al also speculate that naturally occurring AHSP mutations could modify the clinical picture of $\beta$-thalassaemia. There are at least two crucial tests of this idea. First, the offspring produced by mating AHSPdeficient micewith animals heterozygous for $\beta$-thalassaemia might not survive (much like mice with homozygous $\beta$-thalassaemia mutations $\left.{ }^{16}\right)$. Second, in humans, unexplained cases of thalassaemia intermedia in $\beta$-thalassaemia heterozygotes might result from mutations in AHSP that would cause the $\alpha$-chain excess to be more detrimental.

The reverse situation is perhaps more difficult but is also more attractive to a haematologist. Could it be that there are mutations that result in the overexpression of AHSP, so converting thalassaemia major into thalassaemia intermedia? In every large thalassaemia centre there are rare patients, homozygous for a severe $\beta$-globin mutation, who do not depend on transfusions. Perhaps we should be studying the AHSP gene from these people first. If a mutated or overexpressed AHSP gene were so beneficial, one might be tempted to consider it for future gene therapy. In that way, a strict chaperone might become a loving nurse.

Lucio Luzzatto and Rosario Notaro are in the Laboratory of Human Molecular Genetics, IST, National Institute for Cancer Research, Largo

Rosanna Benzi 10, 16132 Genova, Italy.

e-mail: hucia.luzzatto@istge, it

1. Wintrobe, M. M. I, Lah, Clin Med, 17, 899 (1932).

2. Fermi, G. \& Peruta, M. R. Athas of Molecular Structure in Bialogy: Haemogbbin and Myogbb in (Clarendon, Oxford, 1981).

3. Cantor, A. B \& Orkin, S. H. Curr, Opin, Genet, Dev, 11, 513-519 (2001).

4. Grooveld, $\mathrm{F}$ et al, Phil, Traw, R, Sac, Lond. B 339, 183-191 (1993).

5. Van der Ploeg L. H. et al, Nature 283, 637-642 (1990).

6. Higgs, D. R., Sharpe, J. A. \& Wood, W. G. Semin Hemutal 35, 93-104 (1998).

7. Baglioni, C. \& Campana, T. Eur, J. Bịchem, 2, 480-492 (1967).

8. Xihm, A. J. et al Nature 417, 758-763 (2002).

9. Fessas, P. Blood 21, 21 (1963).

10. Thai, S. R. et al, Nature 339, 446-451 (1989)

11. Weatherall, D. J. \& Cleggo J. B. Thalessacmin Symaromes (Blackwell, Offord, 2001).

12. Clegg J. B., Naughton, M. A. \& Weatherall, D. J. J, Mal, Biol, $19,91-108$ (1966).

13. Nathan, D. G., Stossel, T. B, Gunn, R. B, Zarkonaky, H. S. \& Laforet, M. T. J, Clin, hivest, 48, 33-41 (1969).

14. Gabnello, R. et al Blood 62, 1035-104D (1983).

15. Kan, Y. W. \& Nathan, D. G. J. Clin, hnest, 49, 635-642 (1970).

16. Yang B. et al. Proc, Natl Arad, Sri, USA 92, 11608-11612 (1905).
Daedalus

\section{Collimated gas}

A hot gas, says Daedalus, is isotropic. You get the same temperature no matter how you hold the thermometer. If you want the gas to give some anisotropic push, you need a mechanical element - the rocket nozzle and the turbine blade are probably the best known. DREADCO chemists now want to generate anisotropic heat directly. Any fluid becomes isotropic with time, so fast reactions, explosions or rocket-reactions, seem most hopeful. Furthermore, all the energy is stored in the initial molecules. No entering oxygen complicates their anisotropic decomposition.

In this connection Daedalus recalls gunpowder, one of the cleverest of chemical inventions. At present it is made by simple mixing. The DREADCO team are devising a 'linear gunpowder' in which carbon fibres are laid alongside or interwoven with sulphur fibres (made by pouring molten sulphur into water), and these are interwoven with potassium nitrate whisker crystals. The resulting linear product, carefully aligned, should burn in the fibre-direction much faster than in the perpendicular one. Its gas will be hotter and moving faster in that direction, and colder at right-angles. The average temperature will, however, be as for normal gunpowder.

Even a small effect will be well worth having. In burning, linear gunpowder will eject an already-oriented gas. In a rocket, it will give added thrust. The rocket nozzle will have less to do, and will be burnt away more slowly by the cool sideways gas it feels. The DREADCO team also recalls how cordite is extruded as a gel in acetone - perhaps this too could be molecularly aligned anisotropically, thus gaining efficiency. The military would certainly value even a slight increase in the thrust of its rockets.

Of course, the biggest solid-fuel rockets are those of cold-war weapons and the Space Shuttle. Aligned and anisotropic fuels for these monsters could make them even more effective. On a smaller scale, the brass cartridge-case is now filled in bulk with isotropic propellant. Any ordinary gun would benefit from an oriented cartridge whose anisotropic propellant delivered its highvelocity molecules preferentially to the bullet and the breech, with less wasteful heating directed sideways at the barrel. And, of course, the delicate art of making fast-and slow-burning fuses for mining and quarrying would be greatly expanded. David Jones 